Os primeiros psicanalistas: atas da Sociedade Psicanalítica de Viena 1906-1908 - Vol. I Hermann Nunberg e Ernest Federn (Orgs.) Marcelo Checcia, Ronald Torres e Waldo Hoffman(Orgs. da ed. brasileira) São Paulo: Scriptorium, 2015, 583 págs.

\title{
Arquivos da psicanálise: a construção do freudismo
}

Em 1902, Freud buscava ansiosamente recrutar adeptos para as suas descobertas, anunciadas dois anos antes, no "livro dos sonhos". Precisava fazer algo que o tirasse de suas "noites enfadonhas", de seu splendid isolation e o "reanimasse", "revigorasse" como ele costumava relatar a Fliess (Masson, 1985).

Os primeiros a embarcar nessa aventura, que iria "impactar o mundo", foram Alfred Adler, Wilhelm Stekel, Rudolf Reitler, Max Kahane. Um círculo pequeno de médicos que passou a frequentar a Berggasse 19, semanalmente, após as 21 horas. Eles se reuniam em uma sala esfumaçada por charutos e cigarros que consumiam com café e biscoitos, em

*1 Pontifícia Universidade Católica de São Paulo - PUC-SP (São Paulo, SP, Br). 


\section{RESENHAS BIBLIOGRÁFICAS}

torno de uma mesa oval, envoltos em discussões intermináveis, no estilo "banquete socrático" (Roudinesco, 2014). Logo foram chegando intelectuais, quase todos judeus, representativos da cultura da Mitteleuropa, ligados à arte, literatura, filosofia, como Paul Federn, Hugo Heller, Max Graff, Eduard Hirschmman, Isidor Sadger e Fritz Wittels. Estava fundada a primeira instituição da história do freudismo: a Sociedade Psicológica das Quartas-feiras.

Os debates eram acalorados, por vezes violentos, a ponto do "Prof. Freud" intervir e "aconselhar moderação". Todos eram obrigados a falar, por ordem de sorteio, e sobre os mais variados temas: medicina, literatura, arte, política ou ainda sobre os seus próprios sonhos, sofrimentos e os de seus pacientes. Discutiam, também, sobre o "mundo novo" que o inconsciente freudiano descortinava, interrogando a "dimensão biológica e psicológica da sexualidade". Por sua vez, o mestre ensinava aos seus discípulos seu método, iniciando-os na prática psicanalítica, ao mesmo tempo em que refletia sobre conceitos como transferência, pulsão, libido, trauma, neurose, entre tantos.

Foi somente em 1906 que, sob os cuidados de Rank, as reuniões passaram a ser registradas de maneira sistemática, inaugurando um procedimento que seria mantido até 1918, e que fez desses documentos preciosos os primeiros arquivos da psicanálise.

No final dos anos 1950, essas Atas foram compiladas por Nunberg e Federn e publicadas em quatro volumes, entre 1962 e 1975 (vol. I: 1906-1908; vol. II: 1908-1910; vol. III: 1910-1911; vol. IV: 1912-1918) e, a seguir, traduzidos nos Estados Unidos, Argentina, França e Inglaterra.

Agora, com uma cuidadosa tradução, a partir da edição alemã de 2008, finalmente chega ao Brasil o primeiro volume, sob a responsabilidade de Marcelo Checchia, Ronaldo Torres e Waldo Hoffmann que assinam o prefácio pela editora Scriptorium.

Como toda fonte primária, as Atas podem ser lidas e exploradas de inúmeras maneiras, naquilo que revelam sobre a linguagem e as problemáticas da época, no que informam sobre a teoria e a clínica em permanente construção. Nesse volume, que contempla uma excelente introdução de Nunberg, entre tantos, o leitor pode perceber como algumas ideias precisaram de muito tempo de maturação, tal qual as de Stekel sobre as pulsões de vida e de morte, esboçadas em abril de 1907, e só desenvolvidas em "Além do princípio de prazer" (1920).

Do ponto de vista societário, pode-se notar a passagem de um período, que Adler e Federn qualificaram de "comunismo intelectual", para um outro mais estruturado e vertical, desde a dissolução da Sociedade e da fundação 
da Wierner Psychoanalytische Vereinigung (WPV), em outubro de 1907, quando já contava com 19 membros. Nesse processo, alguns ganharam destaque enquanto outros se tornaram silenciosos. Na mesma medida em que as posições foram ficando mais claras, uns deixaram a cena, novos adeptos chegaram, e de diferentes lugares. Foi o caso de Jung e Binswanger, da prestigiosa Escola de Zurique, ou ainda de Eitingon, que participaram de algumas reuniões enquanto convidados. Foi quando, pela primeira vez, a doutrina flertou com a psiquiatria, no tratamento da psicose.

Mas nesse período, em Viena, dentre os membros mais atuantes, havia o "apóstolo" Stekel, por quem Freud nutria simpatia, reconhecia o talento e admirava a capacidade inventiva, mas que também incomodava com a agressividade com que tratava os colegas. Freud também ficava igualmente exasperado com os comentários do "fascinado" Wittels, principalmente pela sua "extrema falta de delicadeza" e "misoginia".

Por outro lado, havia Adler, médico brilhante, simpatizante de esquerda, que recusava a posição de discípulo e em suas intervenções sempre marcava as discordâncias ao enfatizar a dimensão organicista da sexualidade. Sem nunca aderir efetivamente à doutrina, esse primeiro dissidente da história do

574 freudismo seguiu no grupo com parcimônia até 1911, enquanto amadurecia suas teses sobre adaptação ao meio, complexos de superioridade e inferioridade, que mais tarde se tornariam centrais em sua Psicologia Individual.

Já o respeitado Max Graf, o pai do pequeno Hans, costumava liderar interrogações entusiasmadas sobre a "psicanálise aplicada" à literatura e à arte, ou o significado de uma psicologia dos artistas e escritores.

Dentre as contribuições do mestre, os organizadores do livro destacam e com razão a síntese da apresentação e discussão do célebre "caso do Homem dos Ratos". Merece consulta tanto a que consta nas Atas de 30 de outubro e 6 de novembro de 1907, como as menções sobre o seu desenrolar em atas posteriores, pelos argumentos nem sempre presentes no relato publicado em 1909.

Por essas e tantas outras fontes de pesquisa que revela, cabe saudar a iniciativa dos organizadores da edição brasileira. Uma obra imprescindível na biblioteca de todo estudioso e clínico da psicanálise.

\section{Referências}

Masson, J. M. (ed.). (1986). A correspondência Sigmund Freud para Wilhelm Fliess (1889-1904). Rio de Janeiro: Imago. 


\section{RESENHAS BIBLIOGRÁFICAS}

Roudinesco, E. (2014). Sigmund Freud en son temps et dans le nôtre. Paris: Seuil.

Citação/Citation: Oliveira, C. L. M. V. de (2016, setembro). Arquivos da psicanálise: a construção do freudismo. Resenha do livro Os primeiros psicanalisstas: a construção do freudismo. Revista Latinoamericana de Psicopatologia Fundamental, 19(3), 572-575.

Editor do artigo/Editor: Profa. Dra. Sonia Leite

Recebido/Received: 19.10.2015/ 10.19.2016 Aceito/Accepted: 20.12.2016 / 12.20.2016

Copyright: (C) 2009 Associação Universitária de Pesquisa em Psicopatologia Fundamental/ University Association for Research in Fundamental Psychopathology. Este é um artigo de livre acesso, que permite uso irrestrito, distribuição e reprodução em qualquer meio, desde que o autor e a fonte sejam citados / This is an open-access article, which permits unrestricted use, distribution, and reproduction in any medium, provided the original authors and sources are credited.

\section{Carmen lucia M. Valladares de Oliveira}

Psicanalista; Doutora pela Université Paris VII; Pós-doutorado em Psicologia Clínica pelo Laboratório de Psicopatologia Fundamental da Pontifícia Universidade Católica de São Paulo - PUC-SP (São Paulo, SP, Br); Cocordenadora e Profa. do Curso de Especialização em Teoria Psicanalítica da Pontifícia Universidade Católica de São Paulo - PUC-SP; Membro da Société Internationale d'Histoire de la Psychiatrie et de la Psychanalyse - SIHPP e da Associação Universitária de Pesquisa em Psicopatologia Fundamental - AUPPF (São Paulo, SP, Br). Autora de diversos artigos em publicações nacionais e estrangeiras e do livro História da psicanálise. São Paulo 1920-1969. São Paulo: EscutaFapesp, 2005.

Rua Caetés, 646 - Perdizes 05015-081 São Paulo, SP, Br luciavalladares1@gmail.com

\section{(cc) BY-NC}

This is an open-access article, which permits unrestricted use, distribution, and reproduction in any medium for non-commercial purposes provided the original authors and sources are credited. 